\title{
Comparison of Thrombolytic Therapies With Mutant tPA (Lanoteplase/SUN9216) and Recombinant tPA (Alteplase) for Acute Myocardial Infarction
}

\author{
Nobuhiko Ogata, MD; Hisao Ogawa, MD*; Yasuhiro Ogata, MD; Yuichi Numata, MD; \\ Yasuhiro Morigami, MD; Hisakazu Suefuji, MD*; Hirofumi Soejima, MD*; \\ Tomohiro Sakamoto, MD*; Hirofumi Yasue, MD*
}

\begin{abstract}
The fibrinolytic capacity of patients with acute myocardial infarction (AMI) is known to be impaired. The primary regulatory element of the fibrinolytic system is plasminogen activator inhibitor (PAI). It has been previously observed that there are 2 peaks in the plasma PAI level of AMI patients at $4 \mathrm{~h}$ and $16 \mathrm{~h}$ after thrombolytic therapy with recombinant tissue plasminogen activator (rtPA). Lanoteplase/SUN9216 is a mutant tPA with a biological half-life longer than that of rtPA. Thrombolytic therapy with mutant tPA or rtPA was carried out consecutively in 21 patients with AMI (8 patients as the mutant tPA group, and 13 patients as the rtPA group). The recanalization time of the mutant tPA group was significantly faster than that of the rtPA group $(16.1 \pm 3.9$ min vs $39.6 \pm 4.8 \mathrm{~min}, \mathrm{p}<0.01$ ). The PAI activity at $4 \mathrm{~h}$ after the initiation of thrombolysis was significantly lower in the mutant tPA group than in the rtPA group $(8.74 \pm 5.46 \mathrm{IU} / \mathrm{L}$ vs $26.74 \pm 3.35 \mathrm{IU} / \mathrm{L}, \mathrm{p}<0.01)$. There was a one mild peak in serial plasma PAI activity levels $24 \mathrm{~h}$ after the initiation of thrombolysis. The results suggest that thrombolytic therapy with mutant tPA reduced the impairment of fibrinolytic capacity. The mutant IPA gives faster recanalization and lower PAI activity after successful thrombolysis, compared with rtPA. (Jpn Circ J 1998; 62: 801-806)
\end{abstract}

Key Words: Acute myocardial infarction; Mutant tissue plasminogen activator; Plasminogen activator inhibitor; Thrombolytic therapy

$\mathbf{T}$ here is now increasing evidence that coronary thrombosis plays a pivotal role in the pathogenesis of acute myocardial infarction (AMI) and that early thrombolytic therapy reduces mortality in patients with AMI ${ }^{-7}$ However, a problem remains in that approximately $20-30 \%$ of the infarct-related coronary arteries are resistant to thrombolytic therapy, 89 and reocclusion of the recanalized coronary arteries occurs in 10-20\% of patients after recanalization?,10-13 We and other investigators have reported that the fibrinolytic capacity of patients with AMI is impaired ${ }^{14-17}$ The net fibrinolytic activity in plasma is determined mainly by the balance of plasminogen activator inhibitor (PAI) and tissue plasminogen activator (tPA) $!^{77}$ We previously observed 2 peaks of PAI activity after successful thrombolytic therapy in AMI patients; the elevated PAI activity after thrombolytic therapy might attenuate the impairment of fibrinolytic capacity following recanalization of the infarct-related coronary arteries ${ }^{16,18,19}$

Lanoteplase/SUN9216 (mutant tPA) is a new variant of tPA with a long half-life in plasma, which has been reported previously as $\triangle \mathrm{FE} 1 \mathrm{X}-\mathrm{tPA}{ }^{20-22}$ The replacement of asparagine in position 117 with glutamine deletes the glyco-

(Received February 12, 1998; revised manuscript received June 26, 1998; accepted July 1, 1998)

Department of Cardiology, Japanese Red Cross Kumamoto Hospital, and *Division of Cardiology, Kumamoto University School of Medicine, Kumamoto, Japan

Mailing address: Hisao Ogawa, MD, Division of Cardiology, Kumamoto University School of Medicine, 1-1-1 Honjo, Kumamoto 860-8556, Japan sylation site in klingle 1. Lanoteplase/SUN9216 has no finger domain or growth-factor domain in its structure at the N-terminal. Its status as mutant tPA allows for a bolus injection administration route, because its half-life in plasma is longer than that of natural recombinant tPA (alteplase) $)^{20-22}$ Its biological half-life in plasma is approximately $15 \mathrm{~min}$ in healthy young Japanese adults. Because thrombolytic therapy with mutant tPA gave much higher levels of immunoreactive tPA compared with thrombolytic therapy using recombinant tPA, the use of this mutant tPA could promote earlier recanalization of infarct-related coronary arteries? ${ }^{20-22}$

Our present study was designed to identify the differences in clinical outcomes and the change of fibrinolytic capacity in AMI patients who underwent intravenous thrombolytic therapy with mutant tPA or recombinant tPA.

\section{Methods}

\section{Patients}

All patients were diagnosed as having AMI on the basis of typical chest pain lasting longer than $30 \mathrm{~min}$ with STsegment elevation of more than $0.2 \mathrm{mV}$ in 2 continuous leads on a standard 12-lead electrocardiogram (ECG). Patients with severe liver disease, septicemia, disseminated intravascular coagulation, cardiogenic shock, and contraindications for thrombolytic therapy according to the guidelines of the American College of Cardiology/American Heart Association (ACC/AHA) Committee were excluded 
from this study. The patients whose infarct-related coronary arteries spontaneously recanalized during the coronary angiography before the administration of tPA were also excluded. Immediately after the patients were diagnosed as having AMI, they underwent emergency coronary angiography for thrombolytic therapy with either mutant tPA or recombinant tPA. Patients whose infarct-related coronary arteries failed to recanalize to thrombolysis-inmyocardial-infarction (TIMI) ${ }^{23}$ grade 2 or 3 within 60 min after the initiation of the tPA administration were also excluded from the study. Twenty-one patients with first Qwave AMI who underwent thrombolytic therapy with mutant tPA (8 consecutive patients) or recombinant tPA (13 consecutive patients) within $6 \mathrm{~h}$ after the onset of symptoms were eligible for this study. Written informed consent was obtained from each patient and from their family. The protocol of this study was in agreement with the guidelines of the Ethics Committee at our institutions.

\section{Coronary Angiography}

All patients underwent emergency coronary angiography using Judkin's technique. The infarct-related coronary artery was defined as a major coronary artery perfusing the area compatible with the distribution of ST-segment elevation on a 12-lead ECG. All patients underwent a repeat coronary angiography about 3 weeks after admission.

\section{Thrombolytic Therapy}

In the catheterization laboratory used for the emergency coronary angiography, 500-1000 $\mathrm{g}$ of isosorbide dinitrate (ISDN) was injected into the infarct-related coronary artery. If the infarct-related coronary artery remained occluded (TIMI grade 0), an intravenous infusion of tPA was carried out using the following protocols. In the recombinant tPA group, $41.4 \pm 0.03 \mathrm{mg}$ of alteplase (GRTPA, Tanabe Seiyaku Co, Osaka, Japan) was administered over a 60 -min period $(10 \% \text { administered as a bolus })^{24}$ In the mutant tPA group, $11.1 \pm 1.9 \mathrm{mg}$ of lanoteplase/SUN9216 (SUNTORY Ltd, Tokyo, Japan) was administered intravenously as a bolus within a 4-min period.

\section{Patency of the Infarct-Related Coronary Artery}

Coronary angiography was performed immediately before and after the ISDN injection, and at 15-min intervals from the initiation of tPA administration. Patency of the infarct-related coronary artery was assessed according to the TIMI perfusion criteria, 23 in which coronary occlusion was defined as grade 0 or 1 and coronary patency as grade 2 or 3 . The patency of the infarct-related coronary arteries was assessed by 2 independent observers who were unaware of the tPA grouping. The recanalization time was defined as the period from the initiation of the tPA administration until the development of recanalized coronary flow to better than TIMI grade 2 .

\section{Blood Sampling}

Venous blood samples for measuring PAI activity and immunoreactive tPA were obtained immediately before the administration of heparin and other drugs from an antecubital vein without stasis. Venous blood $(4.5 \mathrm{ml})$ was collected into an evacuated tube that contained $0.5 \mathrm{ml}$ of citrate sodium $(0.13 \mathrm{~mol} / \mathrm{L}, \mathrm{pH} 7.5)$. All blood samples were immediately centrifuged at $3000 \mathrm{rpm}$ for $10 \mathrm{~min}$ at $4{ }^{\circ} \mathrm{C}$, and aliquots of samples were stored at $-80^{\circ} \mathrm{C}$ prior to analysis. Venous blood samples were also obtained $1 \mathrm{~h}$ after the initiation of the thrombolytic therapy, at 4-h intervals over the first $24 \mathrm{~h}$, and every morning for the first week.

\section{Determination of PAI Activity}

PAI activity levels were measured with a chromogenic single point poly D-lysine stimulated assay kit (Biopool Inc, Umea, Sweden), expressed as international units per milliliter (IU/ml). The normal value for PAI activity in normal subjects in our laboratory was $5.4 \pm 0.5 \mathrm{IU} / \mathrm{ml}$.

\section{Determination of Immunoreactive $t P A$}

Immunoreactive tPA levels were measured with the commercial enzyme-linked immunosorbent assay kit (Diagnostica Stago Inc, Fracoville, France), expressed as nanogram per milliliter $(\mathrm{ng} / \mathrm{ml})$. The normal value for the immunoreactive tPA levels in normal subjects in our laboratory was $5.8 \pm 0.3 \mathrm{ng} / \mathrm{ml}$.

\section{Statistics}

The clinical characteristics of the mutant tPA group and the recombinant tPA group were compared using the unpaired t-test for continuous data and the Chi-square test for group data. The significance of changes of plasma PAI activity and immunoreactive tPA were evaluated by oneway analysis of variance for repeated measures. The unpaired Student's t-test was used to compare the base levels of plasma PAI activity and immunoreactive tPA and the values of the 2 groups over time. Data are expressed as mean \pm SEM.

\section{Results}

\section{Patients Characteristics}

There was no significant difference in patient characteristics between the mutant tPA group and recombinant tPA group, as shown in Table 1. There was no significant difference in sex, age, serum total cholesterol, triglyceride or heart rate on admission, systolic blood pressure on admission or incidence of diabetes. In the recombinant tPA group, 13 patients were underwent thrombolytic therapy of the left anterior descending artery (LAD) $(n=7)$, the right coronary artery (RCA) $(n=4)$, or the left circumflex artery $(\mathrm{LCX})(\mathrm{n}=2)$. Twelve patients were in Killip class I and 1 patient was in Killip class II. Ten patients belonged to Forrester subset I and 3 patients belonged to Forrester subsets II-IV. In the mutant tPA group, 8 patients underwent thrombolytic therapy of either the LAD $(n=5)$, the RCA $(n=1)$ or the LCX $(n=2)$. All patients were in Killip class I. Seven patients belonged to Forrester subset I and only 1 patient belonged to Forrester subsets II-IV.

\section{Clinical Outcomes}

As shown in Table 2, in the mutant tPA group, the recanalization times were significantly faster than those of the recombinant tPA group $(p<0.01)$. The peak levels of creatine kinase $(\mathrm{CK})$ in the mutant tPA group were significantly higher than those in the recombinant tPA group $(p<0.05)$. There was no significant difference in the patency of the infarct-related coronary arteries at discharge between the 2 groups. No major complications such as intracranial or gastrointestinal bleeding occurred in either group. 
Table 1 Baseline Patient Characteristics

\begin{tabular}{|c|c|c|c|}
\hline & $\begin{array}{c}\text { Recombinant t }_{(n=13)} \\
\text { RA }\end{array}$ & $\begin{array}{c}\text { Mutant tPA } \\
\quad(n=8)\end{array}$ & Difference between groups \\
\hline \multicolumn{4}{|l|}{ Sex } \\
\hline Male & 8 & 6 & \\
\hline Female & 5 & 2 & $N S$ \\
\hline \multicolumn{4}{|l|}{ Age (years) } \\
\hline$\leq 64$ & 6 & 6 & \\
\hline$\geq 65$ & 7 & 2 & $N S$ \\
\hline Tryglyceride $(\mathrm{mg} / \mathrm{dl})$ & $151.7 \pm 22.8$ & $166.5 \pm 40.4$ & $N S$ \\
\hline Total cholesterol $(\mathrm{mg} / \mathrm{dl})$ & $204.2 \pm 14.9$ & $206.3 \pm 10.1$ & $N S$ \\
\hline Heart rate on admission (beat/min) & $71 \pm 7$ & $74 \pm 7$ & $N S$ \\
\hline Systolic blood pressure on admission $(\mathrm{mmHg})$ & $131 \pm 13$ & $132 \pm 8$ & $N S$ \\
\hline Diabetes & $2 / 13$ & $2 / 8$ & NS \\
\hline \multicolumn{4}{|l|}{ IRCA } \\
\hline LAD & 7 & 5 & \\
\hline$L C X$ & 2 & 2 & \\
\hline$R C A$ & 4 & 1 & $N S$ \\
\hline \multicolumn{4}{|l|}{ Infarction site } \\
\hline Anterior & 7 & 3 & \\
\hline Inferior & 4 & 1 & \\
\hline Posterolateral & 2 & 4 & $N S$ \\
\hline \multicolumn{4}{|l|}{ Vessel disease } \\
\hline 1 & 6 & 5 & \\
\hline 2 & 6 & 3 & \\
\hline 3 & 1 & 0 & $N S$ \\
\hline \multicolumn{4}{|l|}{ Killip classification } \\
\hline$I$ & 12 & 8 & \\
\hline$I I$ & 1 & 0 & $N S$ \\
\hline \multicolumn{4}{|l|}{ Forrester subset } \\
\hline$I$ & 10 & 7 & \\
\hline$I I \sim I V$ & 3 & 1 & NS \\
\hline
\end{tabular}

IRCA, infarct-related coronary artery; LAD, left anterior descending artery; LCX, left circumflex artery; RCA, right coronary artery; NS, not significant.

Table 2 Clinical Outcomes

\begin{tabular}{lccc}
\hline \hline & $\begin{array}{c}\text { Recombinant tPA } \\
(n=13)\end{array}$ & $\begin{array}{c}\text { Mutant tPA } \\
(n=8)\end{array}$ & Difference between groups \\
\hline Recanalization time $(\mathrm{min})$ & $39.6 \pm 4.8$ & $16.1 \pm 3.9$ & $p<0.01$ \\
Peak CK $($ IU/L) & $1527.5 \pm 325.8$ & $3246.6 \pm 857.9$ & $p<0.05$ \\
Patency of IRCA at discharge & 1 & & \\
TIMI 0 & 0 & 0 & \\
TIMI 1 & 0 & 0 & \\
TIMI 2 & 12 & 7 & NS \\
TIMI 3 & $12 / 13$ & $8 / 8$ & \\
Patency rate & & 1 & \\
\hline
\end{tabular}

CK, creatine kinase; IRCA, infarct-related coronary artery; TIMI, thrombolysis in myocardial infarction perfusion criteria; NS, not significant.

\section{Serial Changes of Plasma PAI Activity and Immunoreactive $t P A$}

Fig 1 shows the serial changes in plasma PAI activity and immunoreactive tPA levels in the AMI patients who underwent thrombolytic therapy with recombinant tPA (alteplase). Their plasma PAI activity on admission was higher than that of normal subjects $(11.11 \pm 3.53 \mathrm{IU} / \mathrm{ml})$, then became undetectable during the infusion of recombinant $\mathrm{tPA}$, and increased markedly $4 \mathrm{~h}$ after the initiation of intravenous thrombolytic therapy and formed an early peak $(26.74 \pm 3.35 \mathrm{IU} / \mathrm{ml})$. The level of PAI activity then decreased and again increased to a late peak level $(23.93 \pm 2.96 \mathrm{IU} / \mathrm{ml})$ by $16 \mathrm{~h}$ after the initiation of thrombolysis. The PAI activity remained high over the initial 24 -h period $(20.00 \pm 2.62$ $\mathrm{IU} / \mathrm{ml}$ at $24 \mathrm{~h}$ ) and decreased by the second day. These patients' plasma levels of immunoreactive tPA on admis- sion were higher than that of normal subjects $(8.91 \pm 1.80$ $\mathrm{ng} / \mathrm{ml}$ ), then increased markedly immediately after the

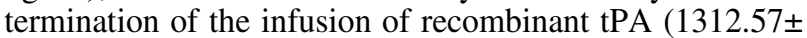
$238.90 \mathrm{ng} / \mathrm{ml}$ ), and decreased rapidly from $4 \mathrm{~h}$ after the initiation of thrombolysis $(31.85 \pm 3.70 \mathrm{ng} / \mathrm{ml})$.

Fig 2 shows the serial changes of plasma PAI activity and immunoreactive tPA levels in the patients with AMI who underwent thrombolytic therapy with mutant tPA (lanoteplase/SUN9216). Their plasma PAI activity on admission was higher than that of normal subjects $(8.00 \pm$ $1.40 \mathrm{IU} / \mathrm{ml})$, then became undetectable at $1 \mathrm{~h}$ after the initiation of the injection of mutant tPA. The activity increased gradually over the 24-h period following the initiation of thrombolysis and formed a one mild peak $(16.36 \pm 3.30$ $\mathrm{IU} / \mathrm{ml})$ at $24 \mathrm{~h}$. The level of PAI activity then decreased to the same level as that at admission by $48 \mathrm{~h}$ after the initia- 

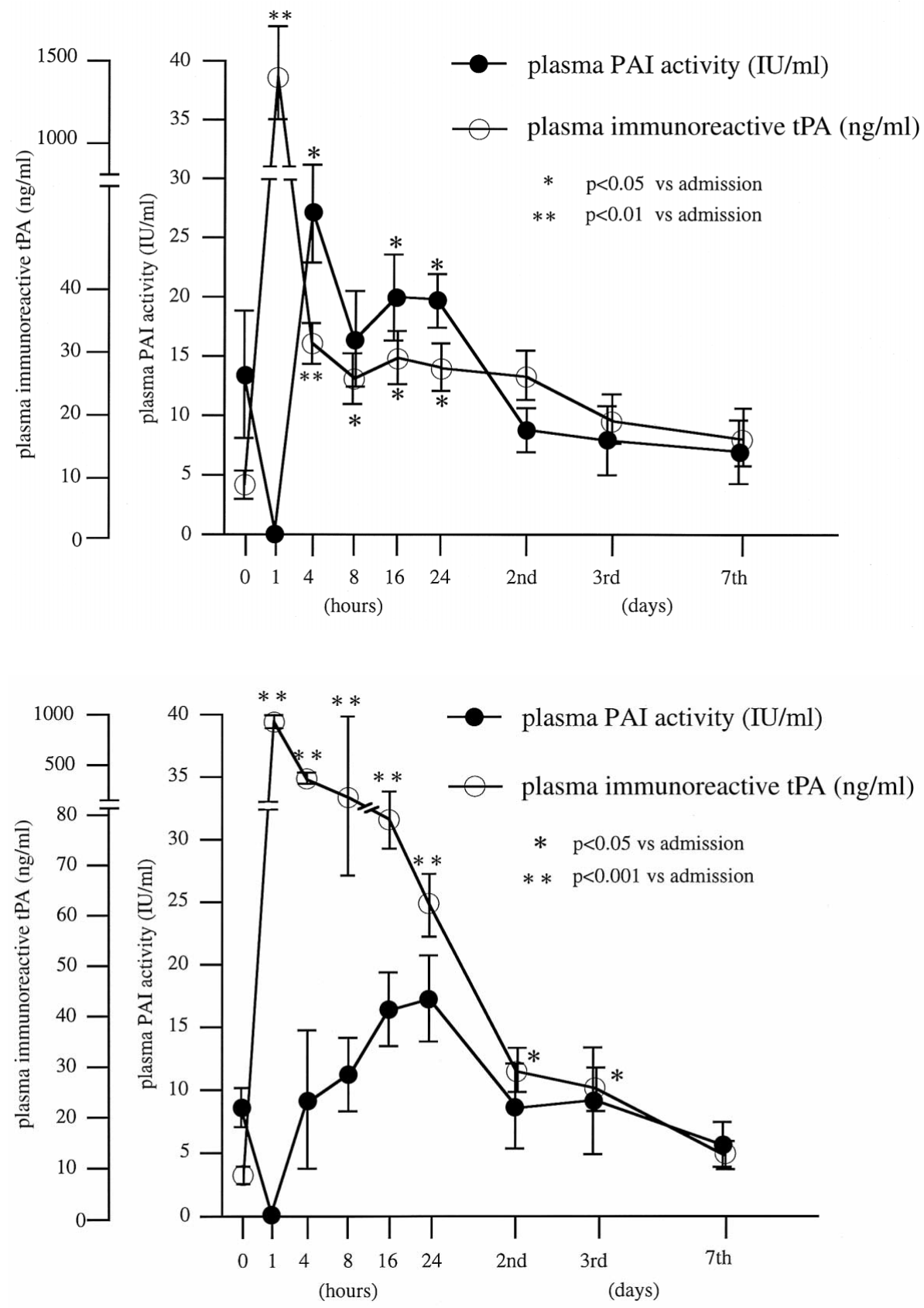

Fig 1. Serial changes in plasma plasminogen activator inhibitor (PAI) activity (solid circles) and immunoreactive tissue plasminogen activator (tPA) levels (open circles) in 13 acute myocardial infarction patients who underwent thrombolytic therapy with recombinant tPA (alteplase). The plasma levels of PAI activity increased markedly $4 \mathrm{~h}$ after the initiation of intravenous thrombolysis and formed an early peak. The plasma levels of immunoreactive tPA increased markedly immediately after the termination of the infusion of recombinant tPA, and decreased rapidly after $4 \mathrm{~h}$ from the initiation of thrombolysis.

Fig 2. Serial changes in plasma plasminogen activator inhibitor (PAI) activity (solid circles) and immunoreactive tissue plasminogen activator (tPA) levels (open circles) in 8 acute myocardial infarction patients who underwent thrombolytic therapy with mutant tPA (lanoteplase/SUN9216). The plasma levels of PAI activity increased gradually $24 \mathrm{~h}$ after the initiation of intravenous thrombolysis (IVT) and formed a one mild peak. The level of PAI activity decreased to the level at the admission by $48 \mathrm{~h}$ after the initiation of IVT. The plasma levels of immunoreactive tPA increased markedly after $1 \mathrm{~h}$ from the initiation of the injection of mutant tPA, and decreased gradually during the 24-h period after the initiation of IVT.

tion of thrombolysis $(8.26 \pm 3.20 \mathrm{IU} / \mathrm{ml})$. The level of PAI activity tended to form a one mild peak, but it was not significant compared with the value of the PAI activity on admission. The plasma levels of immunoreactive tPA on admission were higher than that of normal subjects $(7.23 \pm 1.64 \mathrm{ng} / \mathrm{ml})$, then increased markedly at $1 \mathrm{~h}$ after the initiation of the injection of mutant tPA $(900.76 \pm 58.72$ $\mathrm{ng} / \mathrm{ml}$ ). The levels then decreased gradually during the $24-\mathrm{h}$ period following the initiation of thrombolysis.

Fig 3 shows the comparison of the serial changes in PAI activity between the groups of patients with intravenous thrombolytic therapy with recombinant tPA and mutant tPA. In the mutant tPA group, the plasma level of PAI activity at $4 \mathrm{~h}$ after the initiation of thrombolysis was significantly lower compared with that of the recombinant tPA group $(\mathrm{p}=0.008)$; their PAI activity at 8 and $16 \mathrm{~h}$ after the initiation of thrombolysis was also lower than that of the recombinant tPA group, but the difference was not significant.

The levels of immunoreactive tPA were significantly higher over the initial 24-h period in the mutant tPA group compared with the recombinant tPA group $(61.55 \pm 5.73$ $\mathrm{ng} / \mathrm{ml}$ vs $27.81 \pm 3.60 \mathrm{ng} / \mathrm{ml}$ at $24 \mathrm{~h}, \mathrm{p}<0.001$ ) (data not shown in Fig 3).

\section{Discussion}

Large controlled clinical trials have shown that early thrombolytic therapy reduces the mortality rate of patients with AMI ${ }^{1-7}$ However, there are still some problems with thrombolytic therapies for AMI8,9 One of the most important problems is the reocclusion of recanalized infarct- 


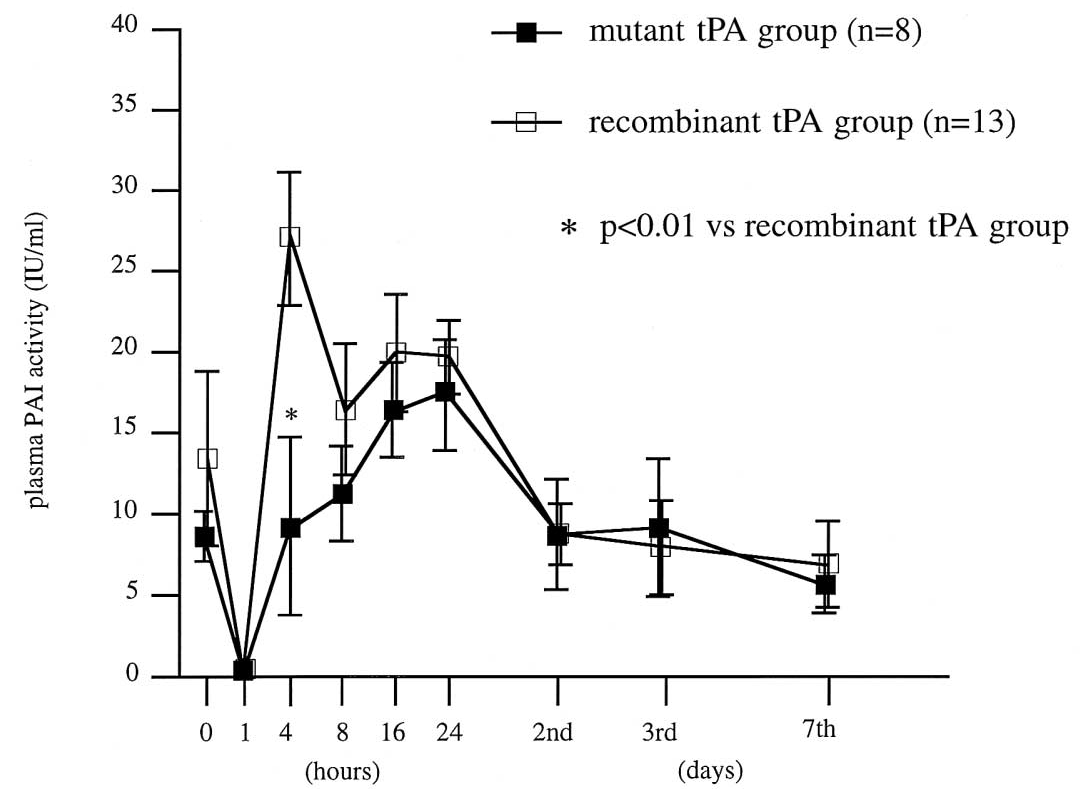

Fig 3. Comparison of serial changes in plasma plasminogen activator inhibitor (PAI) activity between patients who underwent thrombolysis with the recombinant tissue plasminogen activator (tPA) (open squares) and the mutant tPA (closed squares). There was no significant difference in PAI activity between the recombinant tPA group and the mutant tPA group before thrombolytic therapy. The plasma levels of PAI activity at $4 \mathrm{~h}$ after the initiation of intravenous thrombolysis were significantly lower in the mutant tPA group than in the recombinant tPA group $(\mathrm{p}=0.008)$.

related coronary arteries?,10-13 In the study reported here, the recanalization times were significantly faster in the mutant tPA group than in the recombinant tPA group, which is thought to be the result of much higher levels of immunoreactive tPA in the mutant tPA group than in the recombinant tPA group. No bleeding complication occurred in either tPA group. Thrombolytic therapy with mutant tPA seems to be as safe as that with recombinant tPA. However, the safety of this newly developed thrombolytic agent should be carefully investigated, because we examined only a small number of patients in our study. The peak levels of $\mathrm{CK}$ in the mutant tPA group were significantly higher than those in the recombinant tPA group. The timecourses of the serum levels of CK in the mutant tPA group were more rapid than those in the recombinant tPA group $(11.5 \pm 5.1 \mathrm{~h}$ vs $18.9 \pm 3.9 \mathrm{~h}, \mathrm{p}<0.05)$. It seems that the enhancement by changes of the wash-out kinetics of the CK from myocardium is due to the much faster recanalization of the infarct-related coronary arteries in the mutant tPA group than in the recombinant tPA group 25 Nagao et al recently reported that thrombolytic therapy with a bolus injection of mutant tPA achieved rapid recanalization but led to a high rate of reocclusion of infarct-related coronary arteries. ${ }^{26}$ In our study, there was no difference in the patency rate at follow-up coronary angiography between the 2 groups. We cannot make any conclusion about the low rate of reocclusion of infarct-related coronary arteries because only a small number of patients were examined in our study.

The plasma fibrinolytic capacity is known to be impaired in patients with acute coronary syndrome ${ }^{4-17}$ The net fibrinolytic capacity is determined mainly by the balance of PAI and tPA, and the plasma level of PAI activity is one of the major determinants of the fibrinolytic capacity. PAI plays a more important role than tPA in the regulation of the plasma fibrinolytic capacity in most patients with AMI. We found that the PAI activity levels peaked twice after successful thrombolysis with recombinant tPA 19 The first peak, at $4 \mathrm{~h}$ after the initiation of thrombolysis, is thought to be derived from activated platelets and the second peak, at $16 \mathrm{~h}$, is known to be an acute-phase reactant 19,27 The elevated PAI activity may play an unfavorable role in the development of reocclusions after successful thrombolysis 19

The present findings show that the plasma PAI activity was increased on admission and remained high throughout a 24-h period in the AMI patients who underwent thrombolytic therapy with either recombinant tPA or mutant tPA. There was no significant difference in PAI activity between the recombinant tPA group and the mutant tPA group before thrombolytic therapy. The plasma levels of PAI activity at $4 \mathrm{~h}$ after the initiation of thrombolysis were significantly lower in the mutant tPA group than those in the recombinant tPA group $(\mathrm{p}=0.008)$. We suggest that this phenomenon reduced the severity of the impairment of plasma fibrinolytic capacity after thrombolysis in the patients treated with mutant tPA compared with those treated with recombinant $\mathrm{PPA}$. We previously observed that there is a significant correlation between the plasma levels of PAI activity and the patency of the infarct-related coronary artery 16 Our present results suggest that the impairment of fibrinolytic capacity following thrombolytic therapy was less severe in the mutant tPA group than in the recombinant tPA group. Therefore, we conclude that lower PAI activity may improve the impairment of the fibrinolytic capacity in the early phase after successful thrombolysis.

\section{Conclusion}

Thrombolytic therapy with the new mutant tPA (Lanoteplase/SUN9216) produces much faster recanalization of infarct-related coronary arteries and results in lower PAI activity following successful thrombolysis compared with recombinant tPA.

\section{Acknowledgments}

This study was supported in part by a Grant-in-Aid for scientific research, C07670794 from the Ministry of Education, a Research Grant for Cardiovascular Diseases (6A-1 and 7A-3) from the Ministry of Health and Welfare, and a Research Grant from the Smoking Foundation, Tokyo, Japan. This material was presented in part at the 69th Scientific Session of the American Heart Association, New Orleans, Louisiana, 10-13 November 1996. 


\section{References}

1. De Wood MA, Spores J, Notske R, Muser LT, Burroughs R, Golden MS: Prevalence of total coronary occlusion during the early hours of transmural myocardial infarction. N Engl J Med 1980; 303: 897-902

2. Rentrop P, Blanke H, Karsch KR, Kaiser H, Kostering H, Leitz K: Selective intracoronary thrombolysis in acute myocardial infarction and unstable angina pectoris. Circulation 1981; 63: 307-317

3. Mizuno K, Satomura K, Miyamoto A, Arakawa K, Shibuya T, Arai $\mathrm{T}$, et al: Angioscopic evaluation of coronary artery thrombi in acute coronary syndromes. N Engl J Med 1992; 326: 287-291

4. Chesebro JH, Knatterud G, Roberts R, Borer J, Cohen LS, Dalen J: Thrombolysis in myocardial infarction (TIMI) trial, phase 1: a comparison between intravenous tissue plasminogen activator and intravenous streptokinase: clinical findings through hospital discharge. Circulation 1987; 76: $142-154$

5. Gruppo Italiano per lo Studio della Sterptochi-nasi nell'Infarto Miocardico (GISSI). Long-term effects of intravenous thrombolysis in acute myocardial infarction: final report of the GISSI study. Lancet 1987; 2: $871-874$

6. White HD, Rivers JT, Maslowski AH, Ormiston JA, Takayama M, Hart HH: Effect of intravenous streptokinase as compared with that of tissue plasminogen activator on left ventricular function after first myocardial infarction. $N$ Engl J Med 1989; 320: 817-821

7. The GUSTO Investigators: An international trial comparing four thrombolytic strategies for acute myocardial infarction. $N$ Engl J Med 1993; 329: 673-682

8. William DO, Borer J, Braunwald E, Chesebro JH, Cohen LS, Dalen $\mathrm{J}$ : Intravenous recombinant tissue-type plasminogen activator in patients with acute myocardial infarction: a report from the NHLBI thrombolysis in myocardial infarction trial. Circulation 1986; 73: $338-346$

9. Gold HK, Lenbach RC, Garabadian HD, Yasuda T, Johns JA, Grossbard EB: Acute coronary reocclusion after thrombolysis with human tissue-type plasminogen activator: prevention by a maintenance infusion. Circulation 1986; 73: 347-352

10. Ohman EM, Califf RM, Topol EJ, Candela R, Abbottsmith C, Ellis $\mathrm{S}$, et al: Consequence of reocclusion after successful reperfusion therapy in acute myocardial infarction. Circulation 1990; 82: 781 791

11. Topol EJ, Califf RM, George BS, Kereiakes DJ, Abbottsmith CW, Candela RJ: A randomized trial of immediate vs delayed elective angioplasty after intravenous tissue plasminogen activator in acute myocardial infarction. $N$ Engl J Med 1987; 317: 581 - 588

12. Harrison DG, Ferguson DW, Collis SM, Skorton DJ, Ericksen EE, Kioschos JM: Rethrombosis after reperfusion with streptokinase: importance of geometry of residual lesions. Circulation 1984; 69: 991-999

13. Ellis SG, Topel EJ, George BS, Kereiakes DJ, Debowey D, Sigmon $\mathrm{KN}$ : Recurrent ischemia without warning: analysis of risk factors for in-hospital ischemic events following successful thrombolysis with intravenous tissue plasminogen activator. Circulation 1989; 80:
$1159-1165$

14. Barbash GI, Hod H, Roth A, Miller HI, Rath S, Zahav YH: Correlation of baseline with patency of the infarct artery after thrombolytic therapy in acute myocardial infarction. Am J Cardiol 1989; 64: $1231-1235$

15. Hamsten A, de Faire U, Walldius G, Dahlén G, Szamosi A, Landou $\mathrm{C}$, et al: Plasminogen activator inhibitor in plasma: risk factor for recurrent myocardial infarction. Lancet 1987; 2: 3-9

16. Sakamoto T, Yasue H, Ogawa H, Misumi I, Masuda T: Association of patency of infarct-related coronary artery with plasma level of plasminogen activator inhibitor activity in acute myocardial infarction. Am J Cardiol 1992; 70: 271-276

17. Lucore CL, Sobel BE: Interactions of tissue-type plasminogen activator with plasma inhibitors and their pharmacologic implications. Circulation 1988; 77: 660-669

18. Sane DC, Stump DC, Topol EJ, Sigmon KN, Kereiakes DJ, George BS: Correlation between baseline plasminogen activator inhibitor levels and clinical outcome during therapy with tissue plasminogen activator for acute myocardial infarction. Thromb Haemost 1991; 65: $275-279$

19. Hirashima O, Ogawa H, Oshima S, Sakamoto T, Honda Y, Sakata S: Serial changes of plasminogen activator inhibitor activity in acute myocardial infarction: difference between thrombolytic therapy and direct coronary angioplasty. Am Heart J 1995; 130: 933-939

20. Larsen GR, Metzer M, Henson K, Blue Y, Hogen P: Pharmacokinetic and distribution analysis of variant form of tissue-type plasminogen activator with prolonged clearance in rat. Blood 1988; 73: $1842-$ 1850

21. Collen D, Stassen JM, Larsen G: Pharmacokinetic and thrombolytic properties of deletion mutants of tissue-type plasminogen activator in rabbits. Blood 1988; 71: 216-219

22. Hansen L, Blue Y, Barone K, Collen D, Larsen GR: Functional effects of asparagine-linked oligosaccharide on natural and variant human tissue-type plasminogen activator. J Biol Chem 1988; 263: $15713-15719$

23. The TIMI Study Group: The thrombolysis in myocardial infarction (TIMI) trial: phase 1 findings. $N$ Engl J Med 1985; 312: 932-936

24. Ogawa H, Yasue H, Oshima S, Ogata Y, Numata Y, Fujimoto K, for the Kumamoto University Myocardial Infarction Study (KUMIS) Group: Effect of the initial bolus volume of recombinant tissue-type plasminogen activator (rt-PA) on coronary recanalization in and infarct size in Japanese acute myocardial infarction patients. Jpn Circ J 1995; 59: 663-672

25. Robert R: Enzymatic estimation of infarct size. Circulation 1990; 81: $707-710$

26. Nagao K, Satou K, Watanabe I, Arima K, Yamashita M, Ooiwa K, et al: Angiographic study of mutant tissue-type plasminogen activator versus urokinase for acute myocardial infarction. Jpn Circ J 1998; 62: $111-114$

27. Fujii S, Sobel BE: Induction of plasminogen activator inhibitor by products released from platelets. Circulation 1990; 82: 1485-1493 